\title{
POBREZA Y VOLUNTARIADO. Análisis crítico del discurso aplicado a tres programas sociales de la ciudad de Valparaíso*
}

\author{
W. DANIEL VERA ROJAS**
}

\begin{abstract}
RESUMEN
El artículo presenta un estudio sobre los discursos en pobreza producidos por jóvenes voluntarios que participan en tres programas sociales de la ciudad de Valparaíso. La investigación fue de tipo cualitativa-discursiva y se realizaron análisis de textos, entrevistas individuales y grupales semiestructuradas. Un total de tres técnicos responsables de cada programa y 24 jóvenes participaron en el estudio. Los resultados muestran un orden discursivo caracterizado por presentar tres variedades en pobreza: a) en clave individual, b) en clave estructural y c) en clave existencial. En un orden socioinstitucional caracterizado por un proceso de mercantilización de la vida social, pérdida de influencia de la esfera estatal, emergencia de la esfera relacional, y alto consenso en las estrategias de intervención social en pobreza, la primera variedad discursiva circula con mayor autorización y legitimidad; la segunda tiende a estar en proceso de desautorización, y la tercera variedad más bien se invisibiliza, sin perder legitimidad de circulación.
\end{abstract}

Palabras clave: Pobreza, Voluntariado, ANÁLISIS CRÍTICO DEL DISCURSO

* Este artículo es una versión resumida de la investigación presentada por el autor en la Universidad Autónoma de Barcelona para optar al título de Máster en Sociología, mención Políticas Sociales, enero de 2006.

** Universidad Católica de Temuco, Escuela de Trabajo Social, Temuco, Chile. Trabajador Social, Máster en Sociología Universidad Autónoma de Barcelona y Candidato a Doctor en Políticas Sociales de la Universidad de Friburgo, Suiza. E-Mail: wvera@uct.cl. 


\section{RESUMO \\ POBREZA E VOLUNTARIADO. Análise crítica do discurso aplicada a três programas sociais da cidade de Valparaíso}

O artigo apresenta um estudo dos discursos sobre pobreza produzidos por jovens voluntários que participam de três programas sociais da cidade de Valparaíso. A pesquisa foi do tipo qualitativa-discursiva e foram realizadas análises de textos, entrevistas semi-estruturadas individuais e em grupo. Um total de três técnicos responsáveis por cada programa e 24 jovens participaram do estudo. Os resultados mostram uma ordem discursiva caracterizada por apresentar três variedades em pobreza: a) enfoque individual, b) enfoque estrutural e c) enfoque existencial. Numa ordem socio-institucional caracterizada por um processo de mercantilização da vida social, perda de influência da esfera estatal, emergência da esfera relacional e alto consenso nas estratégias de intervenção social na pobreza, a primeira variedade discursiva circula com maior autoridade e legitimidade; a segunda, tende a estar em processo de desautorização, e a terceira variedade se invisibiliza, sem perder a legitimidade de circulação. PALAVRAS CHAVE: PoBREZA, VOLUNTARIADO,
ANÁLISE CRÍTICA DO DISCURSO

\section{Abstract \\ POVERTY AND VOLUNTEERS. Critical analysis of the discourse applied to three social programmes in the City of Valparaíso}

The article presents a study over the discourses on poverty produced by young volunteers that work in three different social programmes of the City of Valparaíso. The research work was of a qualitatitive discursive kind and text analysis were carried out as well as individual and group semi structured interviews. A total of three technicians responsible of each programme and 24 young people took part in the study. The results showed a discursive order noted by presenting three poverty variations: a) individual clue, b) structural clue and, c) existential clue. In a social-institutional order distinguished by a social life merchantilizing process, state sphere loss of influence, surging of the relational sphere and high assent in the poverty social intervention, the first discursive variety appears as the one with higher authorization and legitimacy, the second appears to be in a de-authorization process and the third one is rather invisible, although not loosing circualtion legitimacy.

KEY WORDS: POVERY, VOLUNTEERS, DISCOURSE CRITICAL ANALYSIS 


\section{Presentación}

EL ARTÍCULO PRESENTA UN estudio descriptivo y analítico sobre los discursos en pobreza, presente en las prácticas sociales de «jóvenes voluntarios» que participan en tres diferentes programas sociales: gubernamental, no gubernamental y no gubernamental de carácter religioso.

$\mathrm{Al}$ analizar los discursos sobre pobreza se busca describir y comprender el proceso de significación y problematización que hacen los voluntarios de su práctica social y de ésta, en relación a otras prácticas sociales implicadas en el proceso de producción discursiva del problema, esbozando los diferentes órdenes de discurso que están en disputa en materia de pobreza en el actual contexto de la política social en Chile.

Para este estudio el discurso es comprendido como el lenguaje en tanto «práctica social» imbricada en estructuras sociales, en un proceso recursivo de estructuración, donde práctica social y estructura social se constituyen mutuamente (Fairclough, 2003; Wodak, 2003). Los discursos sobre pobreza se describen a partir de las diferentes narrativas que producen los actores voluntarios, distinguiendo temáticas y variedades discursivas. Estas descripciones a su vez se relacionan con un determinado contexto y práctica social específica.

Durante las dos últimas décadas es posible apreciar la creciente preocupación por parte de los organismos gubernamentales en estas materias, quienes han implementado una diversidad de estrategias y programas de lucha contra la pobreza. Por otro lado, el denominado tercer sector muestra un mayor interés en participar en la definición de los temas y formas de intervención en pobreza, como así una creciente apelación a la sociedad civil y su rol en políticas públicas y sociales. Por último, se observa un interés por parte de organismos multilaterales, en aportar técnica y financieramente en la implementación de este tipo de estrategias (Sanahuja, 2001).

La relevancia de este estudio radica en poder contribuir a la reflexión sobre políticas sociales, y el rol que el voluntariado en particular está adquiriendo en el ámbito de los programas de superación de la pobreza. Los discursos sobre los cuales se sustenta la práctica social de los voluntarios en temas de pobreza incidirían en los efectos que dichas iniciativas puedan producir respecto las personas a quienes se dirigen (Raczynski, 2002). 


\section{ANTECEDENTES}

\section{Pobreza y políticas sociales en Chile}

Chile al término del régimen militar (1988) presentaba una situación en materia de pobreza que alcanzaba al $44,6 \%$ del total de su población, de los cuales $16,8 \%$ se encontraba en situación de indigencia. Por otra parte, las reformas producidas en materia de política social durante este período, no sólo provocaron un aumento de la población pobre, sino además significó un incremento de las tasas de desigualdad social (de Laire, 2004). Sin embargo, según datos del Ministerio de Planificación y Cooperación (MIDEPLAN), Chile muestra avances sustantivos en la lucha contra la pobreza a partir de la década del 90 , observándose una reducción desde un $38,6 \%$ en 1990 a un $20,6 \%$ en el 2000, del total de esta población (MIDEPLAN, 2002). La principal insuficiencia detectada bajo este período ha sido la persistencia de un perfil de desigualdad en la distribución del ingreso. Para el período 1990-1998 es posible observar que $70 \%$ de los hogares del país percibe ingresos inferiores al promedio del país, donde el quintil más pobre de la población se beneficiaba con apenas el 4,5\% del producto y el quintil más rico con el 56,3\% del mismo (MIDEPLAN, 2002).

La década del 90 representa la búsqueda en materia de políticas sociales y de superación de la pobreza, bajo nuevas instituciones, enfoques y metodologías (Serrano y Raczynski, 2003). Se busca una efectiva materialización de la igualdad de oportunidades, partiendo del supuesto que países que tienen una situación más equilibrada en lo social crecerían más rápido, permitirían implementar políticas públicas más eficientes, y presentarían mayor estabilidad política y social. La educación se constituye en la herramienta fundamental y actualizable para la autosuficiencia a través del trabajo, por lo que política social se concentrará en dotar a las personas menos favorecidas de capital humano pertinente (de Laire, 2004; Esping-Anderssen, 2000; Giddens, 1999).

También se aprecia una pobreza diferente a décadas anteriores, cada vez más urbana, con una inserción laboral más diversa, existiendo una fuerte movilidad en torno a la línea de indigencia y pobreza (Serrano y Raczynski, 2003). En el contexto de un país que crece económicamente, también se aprecia una creciente percepción de des- 
igualdad de una parte de la población, ${ }^{1}$ donde la importancia que adquiere la familia de origen pasa a ser más determinante en la probabilidad de que sus miembros puedan ejercer plenamente sus derechos económicos, sociales y políticos (Bengoa, 2005). Esta percepción de desigualdad se fortalece por la experiencia de que el esfuerzo personal no necesariamente lleva al éxito, ni asegura igualdad de derechos. Para los pobres sus posibilidades de movilizar contactos y/o capital social, en pos del éxito y la movilidad social son altamente improbables (Márquez, 2002a; 2002b; 2005).

\section{El concepto de práctica social}

Este estudio analiza los discursos de pobreza producidos por los jóvenes voluntarios, en el contexto de una compleja relación entre una práctica social concreta, la estructura social de una determinada sociedad y la acción social de los individuos. La Teoría Social de la Estructuración (Giddens, 1995) permite establecer una articulación dinámica entre acción y estructura social, y de este modo, acercarse al proceso de mutua implicancia entre ambas categorías. Existe una dualidad de ambos fenómenos, adquiriendo un carácter de recursividad (Cohen, 1997). La práctica social se constituye en la categoría conceptual que permite explicarse al sujeto, el objeto y la relación que se produce entre ambos. Las prácticas sociales poseen capacidad de intervención y modifican el curso y resultado de las actividades sociales, las que pueden conllevar organización secuencial e interactiva de numerosas praxis emprendidas por otros. Estas prácticas sociales se entienden como métodos o técnicas cualificadas, apropiadamente realizados por agentes sociales, quienes tendrán capacidades por medio de dos tipos

$1 \mathrm{Al}$ respecto, un estudio realizado por Cumsille y Garretón, sobre percepción de desigualdad en Chile, muestra a una sociedad que se considera así misma muy solidaria, pero altamente amenazada ante los índices de desigualdad, socavando el sentido de identidad y unidad nacional. Según este estudio, la visión general del país refuerza una idea de una sociedad que, en sus estructuras y valores, consagra y favorece la desigualdad. Así, el clasismo y el individualismo definen las principales características de Chile: más del 60 por ciento considera a Chile «muy clasista», 56 por ciento lo considera «muy individualista», 47 por ciento considera que Chile es «muy solidario», solamente una quinta parte considera que es un país «muy tolerante» y 16 por ciento considera que es «muy democrático» (Cumsille y Garretón, 2005). 
de conciencia: a) conciencia discursiva, que implica la capacidad para expresar con palabras las cosas, y b) conciencia práctica, que conlleva aquello que los actores hacen, siendo este tipo de conciencia la que mayor influencia tiene en la teoría de la estructuración (Giddens y Turner, 1997).

Para esta investigación, la conciencia discursiva de los agentes sociales es comprendida en su capacidad de intervención, y no como mero ejercicio representacional de la realidad. Ciertos enunciados del lenguaje tienen propiedades performativas, constituyéndose en actos de habla en tanto que su enunciación es inseparable de la modificación o creación de un estado de cosas que no podría advenir independientemente de esa enunciación. La dimensión realizativa, emitida en las circunstancias apropiadas, no se limitan a ser una mera descripción de aquello que se hace, sino que rigurosa y directamente lo hacen o realizan (Iñiguez, 2003). Desde un punto de vista sociológico, la pragmática de la comunicación y la capacidad realizativa del discurso, es comprendida atribuyendo un valor especial a las condiciones sociales de producción y circulación de éstas. Esto implica poder establecer la relación que se produce entre determinados hábitus lingüísticos de ciertos locutores sociales (agentes sociales) y los mercados simbólicos (estructura social en su dimensión semiótica) en que se ofrecen dichos productos (Bourdieu, 1985; 1988). La capacidad de acción de los agentes sociales no reside de manera tan enfática en su dimensión individual, sino que se construye, articula y adquiere sentido y poder de acción, en función del contexto en el cual se desarrolla, conformado por acciones del mismo estilo promovidas por otros sujetos, quienes otorgan sentido a una experiencia, a partir de las relaciones que en ella se establecen, producto del intercambio social, inmerso en un contexto social de interdependencia (Gergen, 1996).

\section{La dimensión discursiva de la práctica social}

Para este estudio, la vida social es concebida como una serie de redes interconectadas de prácticas sociales de diferente tipo, y cada práctica tiene un elemento semiótico, el que interviene en dichas prácticas: a) como parte de la actividad social inscrita en una práctica, por medio de una forma particular de uso del lenguaje (pragmática); b) también en las representaciones de otras prácticas, como de las propias, constituyéndose en un proceso de recontextualización de otras prácticas, incorporando esas otras prácticas a la propia (práctica discursiva o 
representacional); c) en las realizaciones de las particulares posiciones existentes en el seno de las prácticas sociales (identidades), atendiendo en la regulación social de la producción, recepción y circulación de discursos en función del contexto sociopolítico (práctica social) (Fairclough, 2003).

Las variedades discursivas son las formas de producción de la vida social en su dimensión semiótica en relación con las diferentes prácticas sociales y posiciones que pueden encontrar en un determinado sistema social. Los estilos de discurso están a su vez condicionados tanto, por las posiciones que ocupan los sujetos en sus respectivas prácticas sociales, como a su vez por las relaciones e identidades que superan la construcción de las posiciones en esas prácticas. Existe una relación dialéctica entre las prácticas discursivas particulares y los ámbitos de acción específicos, que incluyen situaciones, marcos institucionales y las estructuras sociales, en que se hallan ubicados (Wodak, 2003).

Un orden del discurso equivale a la estructuración social de la diferencia semiótica, un particular ordenamiento social de las relaciones entre diferentes formas de generar significado, de producir discursos y variedades discursivas, algunos de los cuales tendrá mayor capacidad para instaurar una normativa semiótica, respecto a otros que jugarán un papel marginal o de oposición al orden discursivo dominante (Fairclough, 2003; Bourdieu, 1985; 1988).

Los discursos sobre pobreza producidos por agentes sociales (voluntarios) que desarrollan una práctica específica, se encuentran en relación de mutua implicancia con un contexto social e institucional, que enmarca las prácticas voluntarias. El contexto estructural es analizado en función de tres dimensiones: esferas de acción (estatal, mercantil, doméstico familiar y relacional), ejes de desigualdad y actores colectivos. Estás dimensiones permiten describir el contexto, como a su vez, la dinámica discursiva (temáticas, variedades y estilos), y su relación con una política social específica, que atribuye diversas valoraciones a las perspectivas sobre pobreza producidas por los voluntarios (Adelantado, Noguera y Rambla, 2000).

\section{El contexto discursivo en pobreza: paradigmas, enfoques y estrategias}

A continuación se presentan aquellos elementos discursivos que están presentes en la conformación del contexto que enmarca la práctica 
social voluntaria en materia de políticas sociales y pobreza. Se describen las diversas narrativas, tanto a nivel de paradigmas de política social, como los diferentes enfoques y estrategias que están presenten en el debate actual sobre el abordaje de la pobreza.

\section{a) Los paradigmas en politica social}

A nivel de paradigmas que orientan la toma de decisiones en política social, es posible encontrar la presencia a lo menos de cuatro discursos que han evolucionado desde perspectivas ideológico-políticas duras a visiones híbridas. a) Discurso neoliberal: el Estado actúa cuando las personas y las familias no pueden resolver por sí mismas los problemas. La interpelación que se hace desde este paradigma para superar la pobreza es a las personas y las familias, por medio del emprendimiento y la capacitación (De Laire, 2004; Oneto, 2005). b) Discurso socialista: es partidaria de un Estado que, sobre la base de una visión solidaria, asegure la cobertura de las necesidades sociales, en niveles mínimos de calidad compatibles con la igualdad social (EspingAndersen, 2000). c) Discurso ecológico: puede ser interpretado como aquel que ubica su centralidad en la relación e integración. El ecologismo no enfoca la mirada sólo en el sujeto, sino también en la posición de éste en una estructura de relaciones. La singularidad semántica de esta mirada dice relación con los fines y los medios, al establecer un fin: la homeostasis, y unos medios: las estrategias de integración (Oneto, 2005). d) Discurso social-identitario: esta nueva perspectiva se articula desde la categoría de la autorrealización como instancia organizadora, en que la modernidad se definirá por el ideal de autenticidad, y no por la autonomía de los sujetos. Se reivindica una visión neocomunitarista, más sensible a las diferencias (Oneto, 2005).

\section{b) Enfoques y estrategias en el abordaje de la pobreza}

Respecto a los enfoques y métodos, utilizados por los diseñadores de estas políticas al momento de definir la pobreza, y que inciden en los modelos de intervención para superarla, es posible apreciar seis. a) Enfoque de las necesidades básicas: plantea la necesidad de definir de manera universal las necesidades básicas humanas, como precondiciones a la existencia humana, prerrequisitos de una vida autónoma dentro de sociedades que poseerían objetivos generales de creación de modos de vida libres y emancipatorias (Doyal y Gough, 1994). b) Enfoque de 
las capacidades y realizaciones: se intenta conciliar pobreza absoluta y pobreza relativa, por medio de su teoría de las capacidades (Sen, 1993). Pobreza no significa sólo carencia o insuficiencia de ingresos, sino un indicador importante de bienestar en tanto permita convertir esos ingresos en capacidades y libertades (Martínez, 1997). El desarrollo humano significa la posibilidad de que toda persona amplíe su capacidad humana y la aproveche al máximo en todas las esferas (económica, social, cultural y política) (PNUD, 1995). c) Enfoque del capital social: el capital social puede ser comprendido como un stock, es decir, como consecuencia de una larga acumulación cultural e histórica que se gesta a lo largo de los años y que constituye un acervo que está introyectado en las conciencias (Fukuyama, 2001; Putnam, 1994; 2000; Serrano, 2005). También puede ser considerado como un flujo, en el contexto de procesos sociales influidos por el entorno y sobre los cuales las personas tienen un ámbito de acción posible (Durston, 2000; 2001). d) Enfoque de la exclusión social: la que acarrea a la persona el riesgo de quedar privada del intercambio material y simbólico con la sociedad en su conjunto, constituyéndose en un fenómeno estructural (De los Ríos, 1999). Este concepto connota carencias no atendibles a partir de la lógica espontánea del mercado, al mismo tiempo que da lugar a la difusión de sensaciones de vulnerabilidad social y pérdida de sentido de pertenencia, lo que sugiere algo más que desigualdad social, puesto lleva consigo el riesgo de una sociedad fragmentada (Castel, 1997; Tezanos, 1997). e) Enfoque de la vulnerabilidad y protección social: se entiende riesgo como la vulnerabilidad de las personas y familias para hacer frente a quiebres o situaciones inesperadas que puedan afectarlos negativamente. El Manejo Social del Riesgo (MSR) alude a la capacidad de las personas y las instituciones de prevenir y enfrentar situaciones de vulnerabilidad. Tiene especial relevancia el concepto de protección social como un componente de una visión más holística de MSR frente a la vulnerabilidad (Holzmann y Jorgensen, 1999; Busso, 2001). f) Enfoque de derechos: se plantea que los Estados deben asumir responsabilidades en la garantía de derechos de todos los ciudadanos, los que comprenden, además de los civiles y políticos, los derechos sociales que constituyen la ciudadanía social (CEPAL, 2000; MIDEPLAN, 2002). Deriva de esta óptica la preocupación por establecer mínimos sociales que son irrenunciables desde el punto de vista de la política pública (Serrano y Raczynski, 2003). 


\section{El contexto discursivo de la práctica voluntaria}

En esta parte se presentan aquellos elementos discursivos constitutivos que enmarcan la práctica voluntaria, haciendo un recorrido desde las diversas perspectivas sobre ciudadanía, así como de los diferentes tipos, momentos y corrientes que están presentes en la acción voluntaria, a nivel mundial y latinoamericano.

\section{a) Ciudadanía y práctica social voluntaria}

La noción de participación ciudadana es entendida como la intervención de los particulares en actividades públicas, en tanto portadores de intereses sociales, la que puede presentar diversas lógicas de acción: la lógica de la eficiencia administrativa; la lógica de la privatización de la gestión desarrollada por el aparato estatal; la lógica de la sustitución de la participación política partidaria; la lógica del estatus público del interés privado; la lógica del mercado sustituyendo al Estado; la lógica de las asociaciones intermedias (Baño, 1998; Noé, 1998).

En Chile se ha impulsado una política de participación ciudadana destinada a establecer nuevos mecanismos de cooperación y articulación entre el Estado y la sociedad civil, bajo las siguientes orientaciones: a) promoción de la asociación voluntaria; b) reforzamiento de la vida corporativa; c) mayor democratización, descentralización y gestión participativa; d) ampliación de los ámbitos de discusión a la dimensión privada; e) restricción del rol del Estado en políticas sociales; f) mayor impacto de programas, movilizando recursos de la propia comunidad; g) legitimación de un campo de mediación entre Estado y personas (Sepúlveda, 2002).

Sin embargo, para algunos autores, estas transformaciones son parte de nuevas políticas sociales de austeridad, que buscan abaratar los costos de los programas sociales, trasladando a la sociedad la responsabilidad de la gestión de parte de los mismos, mediante una cooperación necesaria basada en el principio de «responsabilidad social», que exige una solidaridad de todos ante los problemas sociales (Rodríguez Cabrero, 2002). Este proceso no estaría exento de dificultades, tales como la falta de independencia de estas organizaciones respecto las agencias estatales, la descarga de temas sensibles (la pobreza) en ellas y una relación de autonomía relativa, dependiendo de la financiación del Estado y del sector privado (Rodríguez y Ríos, 2002). Por otro lado, la promoción de la solidaridad como fundamento de una 
política social, resultaría problemática al dejar fuera el tema de la justicia social. Mientras la solidaridad se mueve en el ámbito de la responsabilidad privada, la justicia social conlleva responsabilidades de orden público, de modo que ambos valores suponen consecuencias diferentes para la práctica de una política social específica (Cardarelli y Rosenfeld, 1998; Sandoval, 2002).

\section{b) El voluntariado}

La práctica voluntaria es entendida como actividad humana con sentido para el/los sujetos que la desarrollan, sentido referido a la conducta de otros que la orientan. En el contexto chileno, la noción que define el «trabajo voluntario» es:

Aquel trabajo no remunerado que supone la entrega desinteresada de tiempo, habilidades y capacidades, que se ocupa de las necesidades de otras personas o de la sociedad y se desarrolla en un marco más o menos organizado como una opción libre. La acción voluntaria se ubica dentro de la polaridad entre los derechos sociales y los deberes ciudadanos. $^{2}$

El voluntariado se concreta desde la acción (ejercer un acto voluntario ocasional), pasando por el trabajo voluntario (desarrollar una acción permanente o sistemática), hasta lo que se ha llamado «voluntariado» (acción organizada en el marco de una organización, con una identidad propia, etc.). Éste no establece de manera explícita y exclusiva sus tareas, destinos y territorios, sino se despliega en múltiples y plurales manifestaciones, donde lo constitutivo de su esencia es la acción, la praxis (García Roca, 1994). También se puede entender dicha práctica como una acción en su dimensión de la «responsabilidad» pública hacia el otro, que va más allá de una posible «obligación», sino más bien, en una acción guiada por la conciencia (Jelin, 1996).

2 Consejo Ciudadano para el Fortalecimiento de la Sociedad Civil (2001), Informe al Presidente de la República, Santiago. Dicho Consejo señaló que «entre voluntariado y empleo existen relaciones complejas. No son relaciones de incompatibilidad, aunque no están exentas de riesgo. En este sentido, el voluntariado no es mano de obra barata, así como las organizaciones de la sociedad civil no son un parche para satisfacer necesidades cuya cobertura debe ser una responsabilidad pública estatal». 
Se pueden diferenciar tres tipos de acciones voluntarias: a) Voluntariado asistencial: dignifica el valor de la compañía, de la proximidad, y desarrolla dispositivos orientados a mantener vivo al sujeto, está atento a la dimensión humana de la necesidad y enfatiza la comunicación interpersonal y las relaciones humanas. b) Voluntariado de la rehabilitación: enfatiza las virtudes que tiene toda persona, aun cuanto pueda padecer cualquier discapacidad física, psíquica o social, cuidando la dimensión individual de la necesidad, que es también oportunidad de crecer. c) Voluntariado de la promoción: enfatiza en la generalización de los beneficios sociales, la lucha contra la exclusión y el cambio estructural y enfatiza una acción transformadora, desarrollando dispositivos orientados a prevenir los procesos excluyentes y remover las causas del sufrimiento humano (García Roca, 2001).

Desde la perspectiva de las disposiciones personales hacia la acción voluntaria, es posible identificar dos tradiciones recogidas por diversos estudios. $^{3}$ El voluntariado que busca la transformación social y que provendría en buena medida de la vieja escuela de la militancia política, sindical, cristiana, etc. Por otro lado, se observa el crecimiento de un nuevo tipo de voluntariado que busca la realización personal en un mundo que se muestra más adverso. El voluntariado con compromiso social tiende a mirar la realidad social bajo la perspectiva de que se vive una situación de injusticia que merece una respuesta urgente, y por tanto, se mueve a partir de una ética de la convicción, y la búsqueda de la transformación social. La segunda tradición más bien está ligada a una motivación a conocerse mejor a sí mismo, de probarse, de relacionarse, moviéndose desde una ética de la responsabilidad consigo mismo en primer lugar, valorando los efectos al corto plazo, el trabajo ligado a la cotidianidad, que no renuncia a su vida personal en función del trabajo voluntario que realiza (Aranguren, 2001; Bettoni y Cruz, 2002).

Desde una dimensión más subjetiva, es posible encontrar en la acción voluntaria una alta fuerza motivacional, con gran carga valórica y sentido para sí, donde el amor, en tanto afecto orientador de la

3 En Chile y Latinoamérica se han realizado una serie de investigaciones para conocer tanto el perfil, las motivaciones y las expectativas de los voluntarios que participan en diferentes programas, y que en alguna medida se encuentran bajo las tradiciones que aquí se señalan. Es el caso del estudio realizado por la Fundación para la Superación de la Pobreza (2002), FlACSO (2002), Giacoman y Opazo (2002), Bettoni y Cruz (2002), Jiménez de la Jara (2003), y Zulueta (2003). 
misma, con su carga valórica positiva y en una perspectiva de normativa social, resulta un paliativo subjetivo poderoso frente a la injusticia (Heller, 1977). Pero en un contexto de sociedad moderna, es posible concebir un proceso de construcción de identidad a partir de una referencia valórica asentada en el proyecto de realización del yo, que busca la autenticidad basada en la fidelidad con uno mismo (Giddens, 1993).

Para algunos autores, estos marcos de modernidad imprimen a la acción voluntaria un marcado acento individual, y no colectivo. Bajo estas coordenadas, es posible describir una versión de la acción solidaria caracterizada por: a) la ciudadanía privada: la idea de lo público, lo colectivo, lo estatal queda subsumida y rechazada como símbolo de autoritarismo y falta de libertad, reemplazado por una imagen de organizaciones independientes, autónomas y apolíticas, representantes de una sociedad civil también autónoma y privada que negocia sus intereses particulares o de grupo; b) el consumidor solidario: la solidaridad como valor simbólico se convierte en un objeto/valor acumulable, y por tanto, si el consumo se puede convertir en un acto de solidaridad por medio de campañas y donaciones, también la solidaridad puede legitimar cualquier acto de consumo (Díez, 2002). Se asistiría a un proceso de legitimación de la actividad voluntaria, en un escenario caracterizado por el hundimiento de los grandes proyectos políticos y paradójicamente, por la difusión de un ethos neoindividualista, en que el estatus del voluntariado está cruzado entre la erosión de la fe en lo político y el espiral de la autonomía individual, donde los valores que consagran al individuo y a su libertad son los que permitirían realzar su valoración social (Lipovetsky, 1994).

El voluntariado, como actor de la política social, así como su incidencia en la conformación de los discursos sobre pobreza, adquiere un nuevo protagonismo en un contexto de cambios en la manera de cómo se construye política social, la temática de la pobreza, así como en el propio actor voluntario de estas últimas décadas. Interesa analizar estas nuevas coordenadas en la configuración de las desigualdades sociales, como en la producción discursiva que se está realizando en torno a la pobreza.

\section{MÉTODO}

La investigación utilizó un diseño cualitativo-discursivo, basado en el enfoque histórico del discurso, de la escuela del análisis crítico del discurso (Wodak, 2003). El discurso es comprendido como el conjun- 
to de prácticas lingüísticas de un particular ámbito de la práctica social, las que mantienen y promueven ciertas relaciones sociales (Iñiguez y Antaky, 1994; Pujal y Pujol, 1995; Iñiguez, 1996; 2003; Martín y Wittaker, 1998; Martín, 2003; Fairclough, 2003).

Este enfoque implicó en primer lugar realizar una caracterización discursiva del contexto sociohistórico que enmarca la práctica voluntaria en temas de pobreza, para lo cual se analizan la dinámica de la estructura social de Chile, la influencia de las diversas esferas en la conformación de una determinada política social, así como de la conformación de la acción voluntaria. Estos elementos son los que sirven como elementos interdiscursivos, de manera de poder analizar el componente de estructuración en la dinámica discursiva producida por los programas y voluntarios estudiados. Bajo este contexto son descritas y analizadas las diversas variedades discursivas y sus relaciones en la conformación de un determinado orden del discurso.

Tabla 1

Participantes en el estudio

\begin{tabular}{|c|c|c|c|}
\hline Voluntarios & $\begin{array}{c}\text { Organismo } \\
\text { Gubernamental }\end{array}$ & $\begin{array}{c}\text { Organismo } \\
\text { No Gubernamental }\end{array}$ & $\begin{array}{c}\text { Organismo } \\
\text { No Gubernamental } \\
\text { de carácter religioso }\end{array}$ \\
\hline $\begin{array}{c}\text { Número de } \\
\text { participantes }\end{array}$ & 8 voluntarios & 8 voluntarios & 8 voluntarios \\
\hline Sexo & $\begin{array}{l}5 \text { sexo femenino } \\
3 \text { sexo masculino }\end{array}$ & $\begin{array}{l}4 \text { sexo femenino } \\
4 \text { sexo masculino }\end{array}$ & $\begin{array}{l}3 \text { sexo femenino } \\
5 \text { sexo masculino }\end{array}$ \\
\hline Estudios & $\begin{array}{c}5 \text { universitarios } \\
3 \text { secundarios }\end{array}$ & 8 universitarios & $\begin{array}{c}4 \text { universitarios } \\
2 \text { técnicos superiores } \\
2 \text { secundarios }\end{array}$ \\
\hline $\begin{array}{l}\text { Trayectoria } \\
\text { Voluntaria }\end{array}$ & $\begin{array}{c}8 \text { con más de un año } \\
\text { de experiencia }\end{array}$ & $\begin{array}{c}8 \text { con más de un año } \\
\text { de experiencia }\end{array}$ & $\begin{array}{c}8 \text { con más de un año } \\
\text { de experiencia }\end{array}$ \\
\hline \multicolumn{4}{|l|}{ Técnicos } \\
\hline Profesión & 1 Trabajador Social & 1 Psicóloga & 1 Trabajadora Social \\
\hline Sexo & Masculino & Femenino & Femenino \\
\hline Trayectoria & $\begin{array}{l}\text { Más de } 1 \text { año } \\
\text { de experiencia }\end{array}$ & $\begin{array}{l}\text { Más de } 1 \text { año } \\
\text { de experiencia }\end{array}$ & $\begin{array}{l}\text { Más de } 1 \text { año } \\
\text { de experiencia }\end{array}$ \\
\hline
\end{tabular}

Muestra. La selección de los sujetos participantes se realizó buscando su representatividad en función de un determinado rol y posición social, enmarcado en la trayectoria de trabajo voluntario en temas de pobreza. 
Los criterios muestrales fueron: marco institucional (gubernamental, no gubernamental y religioso), rol (voluntario y técnico), función social (estudiante y profesional), etapa de vida (juvenil). Los grupos de voluntarios fueron conformados respetando los límites institucionales, lo mismo que se aplica en la entrevista individual con los técnicos.

Técnicas de recolección de datos. Se utilizaron entrevistas grupales para los jóvenes voluntarios, entrevistas individuales para los técnicos, y análisis de documentos para las páginas Web institucionales de manera de conocer el marco institucional, misión y objetivos que cada programa se propone.

Procedimiento. En primer lugar, se procedió a determinar el corpus textual ha analizar (textos transcritos de las 3 entrevistas grupales con voluntarios, los textos transcritos de las 3 entrevistas individuales a técnicos de los programas, los textos de las páginas web oficiales de cada programa). En segundo lugar se inició un proceso de análisis «intratextual» a nivel de cada corpus. En tercer lugar, se realizó un primer ejercicio de análisis «intertextual», de modo de comparar y analizar las diversas articulaciones y relaciones que pudieren establecerse entre los diversos textos. En cuarto lugar, se realiza un segundo ejercicio de análisis intertextual e interdiscursivo, de modo de intentar comprender las circunstancias contextuales que enmarcan las relaciones de ciertos tipos de discursos respeto a otros, procediendo a comparar el conjunto de textos trabajados. Por último, se construye un modelo analítico que permitió describir el proceso de interrelaciones de los discursos sobre pobreza en las prácticas sociales de voluntariado, enmarcado en el contexto socioinstitucional aportado por los técnicos, los documentos institucionales y el estudio referencial realizado en materia de políticas sociales y pobreza. La triangulación de los datos sigue un criterio teórico de contexto (macrocontexto, contexto institucional, y los propios discursos de los voluntarios) y otro metodológico (entrevistas grupales, individuales y análisis de textos) (Scollon, 2003; Wodak, 2003).

\section{RESUltados}

A continuación se presenta una síntesis de los principales resultados. La dialéctica analítica entre estos tres niveles, a partir de una actitud de duda metódica, confiere riqueza y densidad a los datos, sin pretensiones de generar categorías independientes de sus observadores y de los contextos históricos que enmarcan estas reflexiones (Ibáñez, 1994). 


\section{Contexto sociodiscursivo de la práctica social del voluntariado en pobreza}

Este contexto hace referencia a la estructura social discursiva en el Chile actual, a nivel de esferas de acción (mercantil, estatal y relacional), de los actores y ejes sobre los cuales se va configurando una determinada manera de hacer práctica social voluntaria en pobreza. Los ejes discursivos principales que caracterizan a este contexto sociodiscursivo pueden resumirse en las siguientes categorías conceptuales.

a) Crecimiento de la esfera mercantil versus disminución de la esfera estatal

Los entrevistados aluden a un proceso de expansión de la esfera mercantil en materia de la regulación de la vida social en Chile, que bajo los criterios de competencia y ganancia, influye en las regulaciones de las otras esferas. Este proceso implica por un lado una progresiva remercantilización de los derechos sociales (Esping-Andersen, 2000) y una pérdida de sensibilización de la sociedad en los temas de pobreza y desigualdad social, por medio de una mercantilización de las relaciones interpersonales, propias de la esfera informal y relacional (ámbito comunitario). Una de las consecuencias de este proceso de traspaso de responsabilidades, sería la paradoja del crecimiento con desigualdad, con un modelo de desarrollo que crece económicamente, pero que presenta a la vez una política social incapaz de distribuir la riqueza generada. Se apela a una narrativa constatada por medio de un malestar social (Cumsille y Garretón, 2005; Márquez, 2005) de algunos sectores más sensibles a la situación de pobreza y desigualdad.

b) Emergencia de la esfera relacional y su participación en la política social

Los entrevistados refieren a un proceso de desarrollo de la esfera relacional que busca restituir sentidos de comunidad y solidaridad social, proceso no exento de contradicciones, pues también se la interpreta como una privatización de los temas de interés público (Rodríguez Cabrero, 2002). Se destaca una mayor implicancia de la esfera relacional en temas públicos, por medio de una estrategia de creciente ciudadanización de la política social, en un contexto de debilitamiento de las formas clásicas de participación política y social de la sociedad 
chilena. Se asiste a la búsqueda de nuevas estrategias de gestión de políticas públicas y de programas de lucha contra la pobreza, promovidas desde una política nacional de participación ciudadana, que contribuye a una visibilización de la sociedad civil. Sin embargo, se autoriza la expresión y circulación de las narrativas de ciudadanización de la política social desde una lógica que no siempre deja claro los objetivos y sentidos que conlleva (Noé, 1998; Sepúlveda, 2002).

\section{c) Revalorización del voluntariado como actor social}

Los entrevistados también dan cuenta de una revalorización social del voluntariado, pero en función de estas nuevas coordenadas de significación, en que la acción se transforma discursivamente desde metadiscursos de orden político-social, hacia relatos más orientados al plano de la autorrealización personal y la búsqueda de relaciones interpersonales (Bettoni y Cruz, 2002). Desde otro punto de vista, la acción solidaria cobra visibilización pública (Zulueta, 2003), se masifica y por tanto, está al alcance de todos poder realizarla, y no queda circunscrita a un segmento de la población que se supone comprometido socialmente (Aranguren, 2001).

\section{Contexto discursivo institucional de la práctica social del voluntariado en pobreza}

De manera de presentar sintéticamente los principales elementos discursivos constituyentes del contexto local de la práctica social del voluntariado en temas de pobreza, se muestra una tabla que resume los discursos, conceptos y enfoques que adoptan cada una de las instituciones estudiadas.

La Tabla 2 muestra los paradigmas institucionales sobre pobreza, que para el caso de este estudio correspondieron a tres organizaciones, las que presentan altos niveles de coincidencia en lo que respecta sus miradas sobre pobreza, como así también, los enfoques y estrategias que promueven en su intervención social. Con matices asistenciales, de promoción o ciudadanos, en general imprimen a su accionar miradas multidimensionales de la pobreza, apuestan por intervenciones centradas en el ámbito psicosocial de las personas pobres, buscan promover la responsabilidad social en jóvenes estudiantes, y tienden a imprimir una labor profesionalizante del voluntariado en pobreza. Con ello, tienden a otorgar un papel menos protagónico a las propias per- 
sonas en situación de pobreza, quizás con la excepción del organismo gubernamental, que asume una perspectiva de derechos ciudadanos en el segmento de población juvenil popular con que trabaja. También es posible advertir un nuevo perfil de voluntariado, conformado en su mayoría por jóvenes universitarios y secundarios, de clase media, que poseen experiencias anteriores en acciones solidarias. Este voluntariado se caracteriza por desarrollar una acción solidaria que se moviliza desde sus intereses y proyectos personales por sobre referencias de orden político y/o ideológico (Aranguren, 2002; García Roca, 1994; Zulueta, 2003). Este voluntariado identifica su accionar solidario como parte de una responsabilidad social que se enmarca en una ética más bien privada de lo social, y que no renuncia mediante su participación solidaria, a la búsqueda del placer de encontrar al otro, el deseo de valorización social, la ocupación del tiempo libre, entre otras motivaciones (Lipovetsky, 1994).

Tabla 2

Matriz descriptiva de contexto discursivo institucional en pobreza

\begin{tabular}{|c|c|c|c|}
\hline & $\begin{array}{c}\text { Organismo } \\
\text { Gubernamental }\end{array}$ & $\begin{array}{c}\text { Organismo } \\
\text { carácter religioso }\end{array}$ & $\begin{array}{c}\text { Organismo } \\
\text { No Gubernamental }\end{array}$ \\
\hline Valores dominantes & Inclusión & Acogida & Integración \\
\hline $\begin{array}{l}\text { Explicación } \\
\text { de la pobreza }\end{array}$ & \multicolumn{3}{|c|}{$\begin{array}{l}\text { Multidemensionalidad: relación de las personas } \\
\text { con sus sistemas }\end{array}$} \\
\hline Ejes política social & \multicolumn{3}{|c|}{$\begin{array}{c}\text { Enfoque de vulnerabilidad, manejo social del riesgo y sistemas } \\
\text { de protección social; valorización de criterios de focalización y } \\
\text { multisectorialidad }\end{array}$} \\
\hline Actores relevantes & $\begin{array}{l}\text { Protagonismo } \\
\text { estatal } \\
\text { y ciudadano }\end{array}$ & \multicolumn{2}{|c|}{$\begin{array}{l}\text { Coordinación sector público, privado } \\
\text { y ciudadano }\end{array}$} \\
\hline $\begin{array}{l}\text { Estrategia } \\
\text { de abordaje }\end{array}$ & $\begin{array}{l}\text { Promoción capa- } \\
\text { cidades y dere- } \\
\text { chos a través del } \\
\text { empoderamiento }\end{array}$ & $\begin{array}{l}\text { Restitución de dere- } \\
\text { chos por medio } \\
\text { de la asistencia }\end{array}$ & $\begin{array}{l}\text { Promoción capacida- } \\
\text { des y derechos } \\
\text { a través del capital } \\
\text { social }\end{array}$ \\
\hline
\end{tabular}

Fuente: Adaptación del modelo diseñado por Oneto (2005).

\section{Temáticas y variedades discursivas sobre pobreza y voluntariado, producidos por los voluntarios}

De manera de presentar sintéticamente las principales temáticas y variedades discursivas sobre pobreza y voluntariado producidas por los voluntarios, a continuación se presenta una tabla que resume las 
variedades discursivas encontradas en función de diferentes ejes temáticos. Cabe señalar que estas variedades se conforman a partir de los elementos encontrados en los discursos de voluntarios provenientes de los diferentes organismos, no existiendo una clara narrativa adscrita a un programa específico.

Tabla 3

Matriz descriptiva de las temáticas y variedades discursivas sobre pobreza y voluntariado

\begin{tabular}{|c|c|c|c|}
\hline Temáticas & $\begin{array}{c}\text { Variedad } \\
\text { Narrativa } 1\end{array}$ & $\begin{array}{c}\text { Variedad } \\
\text { Narrativa } 2\end{array}$ & $\begin{array}{c}\text { Variedad } \\
\text { Narrativa } 3\end{array}$ \\
\hline $\begin{array}{c}\text { Valores } \\
\text { dominantes }\end{array}$ & $\begin{array}{l}\text { Esfuerzo y supera- } \\
\text { ción personal }\end{array}$ & $\begin{array}{c}\text { Igualdad de derechos } \\
\text { y justicia social }\end{array}$ & $\begin{array}{l}\text { Libertad individual } \\
\text { y tolerancia }\end{array}$ \\
\hline $\begin{array}{l}\text { Explicación } \\
\text { de la pobreza }\end{array}$ & $\begin{array}{c}\text { Dimensión familiar } \\
\text { Función afectiva- } \\
\text { normativa. }\end{array}$ & \begin{tabular}{|c|} 
Desigualdad de acceso \\
a las oportunidades \\
sociales \\
\end{tabular} & Énfasis existencial \\
\hline $\begin{array}{c}\text { Metas en } \\
\text { pobreza }\end{array}$ & $\begin{array}{c}\text { Círculo de la pobreza } \\
\text { y dignificación }\end{array}$ & $\begin{array}{l}\text { Igualdad de oportuni- } \\
\text { dades y erradicación }\end{array}$ & $\begin{array}{l}\text { En esta dimensión, esta } \\
\text { narrativa no enfatiza } \\
\text { un variedad específica, } \\
\text { y más bien se subsume } \\
\text { en las otras }\end{array}$ \\
\hline $\begin{array}{l}\text { Mirada } \\
\text { sujeto } \\
\text { pobre }\end{array}$ & $\begin{array}{l}\text { El pobre como } \\
\text { otro diferente }\end{array}$ & $\begin{array}{l}\text { El pobre como parte } \\
\text { de la sociedad }\end{array}$ & $\begin{array}{l}\text { En esta dimensión, esta } \\
\text { narrativa no enfatiza } \\
\text { un variedad específica, } \\
\text { y más bien se subsume } \\
\text { en las otras }\end{array}$ \\
\hline $\begin{array}{c}\text { Miradas de la } \\
\text { acción } \\
\text { voluntaria }\end{array}$ & $\begin{array}{l}\text { Perspectiva } \\
\text { promocional }\end{array}$ & $\begin{array}{c}\text { Perspectiva } \\
\text { ciudadanizadora }\end{array}$ & $\begin{array}{c}\text { Perspectiva } \\
\text { asistencialista }\end{array}$ \\
\hline
\end{tabular}

Fuente: Adaptación del modelo diseñado por Oneto (2005).

Variedad narrativa 1: Esta narrativa se orienta bajo los valores del esfuerzo y la superación personal, y la pobreza es entendida como un problema que si bien posee una relación con aquellos aspectos estructurales de una sociedad, pasa fundamentalmente por las dimensiones personales y familiares de los pobres, especialmente, por la mejora de funciones afectivas y normativas de estos grupos. Con una representación de sujeto pobre como perteneciente a una subcultura y a un círculo social cerrado, sus alternativas de superación pasan por las posibilidades que dichos sujetos y grupos puedan desarrollar, aprender, potenciar y transformar sus cualidades psicosociales en función de modelos de clase media, que se los supone integrados socialmente; los voluntarios se constituyen en los referentes a seguir por parte de estos grupos. 
Variedad narrativa 2: Esta narrativa tiende a imprimir una perspectiva en que priman valores centrados en la igualdad y la justicia social, que asigna protagonismo a la función estatal y social como ejes de superación, y que tiende a explicarse la pobreza como consecuencia de factores socioestructurales que deben ser abordados. En función de las coordenadas discursivas vigentes, este discurso articulado desde una argumentación ética asume una actitud crítica respecto a la estructura de oportunidades existentes en el país. Se apela a la acción del Estado, mediante un protagonismo que garantice una verdadera igualdad de oportunidades a las personas en situación de pobreza. Su imagen de los pobres es como personas iguales en su condición humana, diferenciándolos las circunstancias sociales que les toca vivir. La acción solidaria se inscribe en una perspectiva más bien ciudadanizadora, donde el trabajo voluntario busca promover la conciencia y organización de las propias personas en pro de sus derechos sociales.

Variedad narrativa 3: Existe un tercer discurso que escapa al eje de debate entre lo público y lo privado, o lo individual y lo estructural al momento de referirse a la pobreza. Fundamentado desde una ética de la fraternidad y por medio de una actitud benevolente, este tercer discurso apuesta por una perspectiva de pobreza donde los referentes de orden estructural, políticos o sociales pierden referencia, para dar paso a claves de orden más bien existencial. La pobreza es comprendida como carencia espiritual, y cruza al conjunto de la población, en especial a quienes no demuestran preocupación por el prójimo. Si bien su intervención en pobreza conlleva la adopción de retóricas más promocionales y técnicas por parte de estas prácticas voluntarias, para esta narrativa no implica renunciar del todo a su discursiva existencial, fundamentada en un horizonte ético cristiano que cobra nueva relevancia en un escenario cultural más individualista.

\section{Modelo de relaciones interdiscursivas sobre pobreza y voluntariado}

En esta parte se presenta el modelo que permite no sólo describir, sino analizar la interrelación entre las diversas temáticas y variedades discursivas ya descritas, pero buscando establecer relaciones en función de contexto socioinstitucional que enmarca las prácticas sociales voluntarias. 
Figura 1

Modelo de relaciones interdiscursivas sobre pobreza y voluntariado

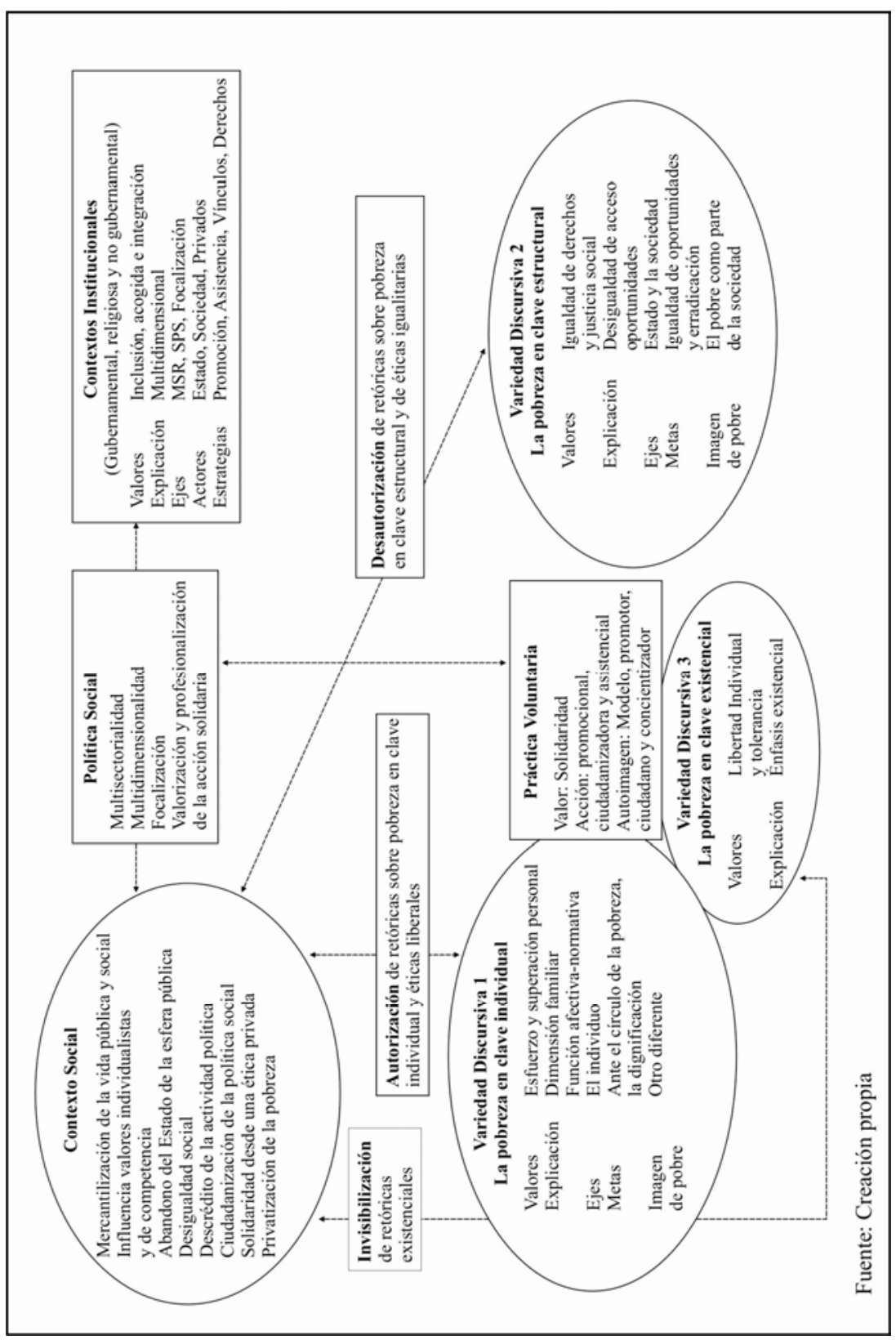


Como se ha señalado anteriormente, el estudio se centra en la dimensión discursiva que toda práctica social posee, específicamente la práctica voluntaria en pobreza, entendiendo que dicha práctica se encuentra inserta en una red de otras prácticas sociales que van conformando una estructura más sostenida en un determinado tiempo y espacio (Fairclough, 2003; Wodak, 2003).

Reconociendo la relación de recursividad entre estructura y acción social, el modelo propuesto intenta hipotetizar sobre un determinado orden del discurso en pobreza a partir de las prácticas voluntarias analizadas. Temáticas, variedades y contextos se interconectan en una red de relaciones, que en este caso, se centra en los discursos sobre pobreza producidos en las prácticas sociales voluntarias. Se busca apreciar la fuerza ilocucionaria de determinadas narrativas, su capacidad para constituir nuevos órdenes simbólicos en temas de pobreza (Bourdieu, 1985).

a) Discurso sobre pobreza en clave individual:

la argumentación pragmática y la actitud optimista

i) La articulación interna del discurso. El primer discurso sobre pobreza lo denominaremos «discurso de pobreza en clave individual», dado que articula de manera coherente narrativas alusivas a valores centrados en el esfuerzo y la superación personal, una explicación de la pobreza con énfasis en la dimensión familiar y que reconoce al individuo como actor central para la superación. También plantea una perspectiva de problema que lo pone fuera del alcance de la sociedad para poder resolverlo, por tanto, aspira sólo a un proceso de suavización de aquellos aspectos más duros de su expresión. Por último, construye una imagen del sujeto pobre como un otro diferente en su condición social y cultural que requiere transformarse y/o mimetizarse para poder aspirar a integrarse a la sociedad.

ii) La «autorización» como relación interdiscursiva. Respecto a la relación de interlocución entre este discurso y el contexto socioinstitucional, es posible indicar que dadas las coordenadas simbólicas de dicho contexto, esta se sostiene en una relación de «autorización» con el presente discurso sobre pobreza, dado un contexto social caracterizado por procesos de mayor influencia de la esfera mercantil en la vida social, y menor influencia de la esfera estatal, lo que produce a nivel simbólico, una mayor influencia de discursos que promueven miradas centradas en las capacidades y autonomías de los sujetos, versus responsabilidades colectivas en materia de desigualdad. 
b) Discurso sobre pobreza en clave estructural:

la argumentación ética de la justicia y la actitud crítica

i) La articulación interna del discurso. Esta segunda narrativa, que denominaremos, discurso de «pobreza como problema socioestructural», articula valores que promueven la igualdad de derechos y la justicia social, explica la pobreza como consecuencia de las desigualdades en el acceso a las oportunidades sociales, sostiene que el eje de la superación pasa en primer lugar por la labor del Estado y del conjunto de la sociedad, se plantea como meta el fin de la pobreza por medio de la igualdad de oportunidades sociales y construye una imagen de pobre que lo valora en su condición de tal, entendiendo que en la diversidad y la tolerancia está la riqueza de la sociedad.

ii) La «desautorización» como relación interdiscursiva. El contexto socioinstitucional marcado por la creciente influencia de la esfera mercantil, y menor presencia de la esfera estatal en materia de desigualdades sociales, caracterizaría una relación más bien difusa. Es posible señalar que la circulación de esta retórica sería «desautorizando», dados las coordenadas narrativas dominantes en el contexto antes descrito. La ética de la justicia social cede espacio a éticas más individuales y pragmáticas, que privilegian las estrategias personales de superación. Desde este discurso se critica y pone en tela de juicio las oportunidades que se ofrecen en materia de educación, salud, vivienda, trabajo al mundo pobre, pues están altamente conscientes de los niveles de desigualdad existentes en la sociedad chilena.

c) Discurso sobre pobreza en clave existencial:

la argumentación ética de la fraternidad y la actitud benevolente

i) La articulación interna del discurso. El tercer discurso en pobreza representa una perspectiva diferente a las dos anteriores, pues si bien éstas se articulan en torno a un mismo eje (público-privado/individuoestructura), esta narrativa construye su discurso en clave existencial, es decir, apelando a la dimensión espiritual y humana que representa la pobreza, sin entrar necesariamente en el ámbito más de orden político estratégico de su problematización. Se conecta con valores como la libertad de elección en términos de opciones de vida, la tolerancia, la aceptación de estas diversas formas, y el humanismo de raíz cristiana, la pobreza se comprenderá como una situación que está presente en el conjunto de la sociedad, y que se relaciona con la dimensión espiritual de las per- 
sonas.

ii) La «invisibilidad» como relación interdiscursiva. El contexto socioinstitucional interpela a este discurso, «invisibilizándolo», pues si bien no lo desautoriza en la conversión pública, lo neutraliza por su mirada tradicional, asistencial y su falta de sentido pragmático para enfrentar temas de pobreza. Su retórica de la compañía, el apoyo y la asistencia cada vez es más desvalorizada, incluso al nivel de provocar en esta misma retórica una adaptación más moderna de la labor de asistencia. Sin embargo, su apelación a la solidaridad, la humanidad, la preocupación por el prójimo, referentes enmarcados en la ética cristiana, adquieren una nueva valorización en un escenario social referido como más individualista y solitario.

Tabla 4

Cuadro síntesis de las variedades discursivas sobre pobreza

\begin{tabular}{|c|c|c|}
\hline $\begin{array}{l}\text { Discurso sobre pobreza } \\
\text { en clave individual: } \\
\text { la argumentación prag- } \\
\text { mática y la actitud opti- } \\
\text { mista }\end{array}$ & $\begin{array}{c}\text { Discurso sobre pobreza en } \\
\text { clave estructural: } \\
\text { la argumentación ética de } \\
\text { la justicia y la actitud } \\
\text { crítica }\end{array}$ & $\begin{array}{c}\text { Discurso sobre pobreza en } \\
\text { clave existencial: } \\
\text { la argumentación ética de } \\
\text { la fraternidad y la actitud } \\
\text { benevolente }\end{array}$ \\
\hline $\begin{array}{c}\text { «Los cambios sociales } \\
\text { nacen de los individuos, } \\
\text { nacen de uno mismo, y de } \\
\text { lo que uno pueda lograr } \\
\text { con otras personas como } \\
\text { uno, y que se proponen lo } \\
\text { mismo. No podemos vivir } \\
\text { pensando por qué el Estado } \\
\text { no hace esto, por qué los } \\
\text { particulares no hacen esto } \\
\text { otro, y uno sin hacer nada. } \\
\text { Todo parte de la base de lo } \\
\text { que lo uno siente. Si a uno } \\
\text { le da lo mismo bien, pero } \\
\text { si a uno no le da lo mismo, } \\
\text { empieza a hacer cosas» } \\
\text { (EGONG1). }\end{array}$ & $\begin{array}{c}\text { «Entonces, creo que todas } \\
\text { las personas deberían tener } \\
\text { las mismas oportunidades, } \\
\text { creo que no todas las perso- } \\
\text { nas somos iguales, somos } \\
\text { diferentes, y debemos res- } \\
\text { petar las diferencias de cada } \\
\text { persona, raciales, sociales, } \\
\text { étnicas, de todo tipo, pero } \\
\text { en base a todas esas dife- } \\
\text { rencias, debemos crear las } \\
\text { oportunidades, y no discri- } \\
\text { minar a nadie, nadie puede } \\
\text { quedar afuera de un proyec- } \\
\text { to de sociedad en que todos } \\
\text { mejoren» (EGOG8). }\end{array}$ & \begin{tabular}{|c|} 
«Claro, este medio, y la \\
vida que tenemos, hablan \\
que pobres son determina- \\
dos grupos de personas. \\
También los medios nos \\
permiten visualizarlo así, \\
pero no sé si pobre es en \\
definitiva, el que se siente \\
pobre, porque uno aún en \\
estos momentos, siendo \\
pobre, pero no me siento \\
pobre. Claro, porque de \\
pronto esta deficiencia \\
espiritual no la voy a califi- \\
car como tal, no pesa más \\
que ver que de pronto sí \\
tengo un plato de comida, sí \\
tengo una casa. Siento esa \\
falta, siento esa hambre, \\
pero para lo cual no hay \\
instituciones, no serían \\
capaces de dar abasto. ¡No \\
habría voluntarios!»
\end{tabular} \\
\hline
\end{tabular}




\begin{tabular}{|l|l|l|}
\hline & & (EGOR6). \\
\hline
\end{tabular}

\section{DISCUSIÓN}

Esta investigación intentó describir los discursos sobre pobreza y voluntariado presente en tres programas sociales específicos, de manera de construir un modelo analítico que diera cuenta no sólo de los discursos, sino del orden discursivo que está sosteniendo la dinámica interna de dichos discursos. El modelo sugiere el poder de autorización y de estructuración que adquieren aquellas retóricas que enfatizan miradas individuales, liberales y modernas de pobreza, por sobre otras perspectivas. La explicación, superación y representación de la pobreza se constituye en torno a un sujeto o grupo social, desvinculándola de los elementos sociales, políticos y económicos que lo circunscriben. Mediante narrativas que apelan al esfuerzo, a la disfunción familiar, a las capacidades personales, a los círculos cerrados de pobreza, a la subcultura, etc., el tema de la pobreza se traslada desde el ámbito de desigualdades estructurales de la sociedad hacia un fenómeno circunscrito a las circunstancias inmediatas que afectan a las personas que viven estas situaciones. En este orden discursivo dominante, la pobreza se construye como problema del ámbito personal, familiar y subcultural de los propios pobres, quienes mediante una serie de estrategias de adaptación, desarrollo y transformación deben movilizarse en función de patrones culturales de los grupos sociales integrados, y con ello la pobreza se invisibiliza como problema sociopolítico, quedando reducido a una mirada psicosocial (Cardarelli y Rosenfeld, 1998; Márquez, 2005).

La pobreza como problema social, se moderniza en cuanto enfoques, estrategias y perspectivas de intervención social. Se enfatizan conceptos que privilegian modelos de vulnerabilidad, sistemas de protección social, teorías de vínculos y apoyo social, entre otras. Estas herramientas contribuyen a una mayor tecnologización y profesionalización de la práctica social en pobreza, pero junto a ello, un proceso de debilitamiento del debate político y social en materia de desigualdades sociales. Por otro lado, el traspaso de responsabilidades hacia el tercer sector y la ciudadanización clientelar de la política social, refuerza aún más la despolitización creciente del tema de la pobreza. Las organizaciones adquieren competencia en el tema de la pobreza, en función de sus capacidades técnicas, y los voluntarios en función de su eficacia y compromiso ciudadano concreto y apolítico (Díez, 2002; Rodríguez Cabrero, 2002). 
A nivel de los paradigmas éticos y políticos que mayor circulación adquieren en este orden discursivo, se aprecia un traslado desde una ética social pública, hacia otra de carácter privado. La pobreza es por un lado responsabilidad de las propias personas que viven esta situación, como a su vez, del conjunto de la sociedad, bajo la narrativa de la responsabilidad social. La justicia e igualdad de oportunidades se movería desde el ámbito del deber y derechos sociales hacia una práctica de responsabilidad y solidaridad que les compete a todos los ciudadanos, pero en apelación a su fuero interno (Lipovetsky, 1994). Se estaría produciendo una transformación en las categorías discursivas sobre derechos civiles y políticos, que reducen la dimensión social a una expresión asistencial y marginal. Las retóricas autorizadas dan cuenta de estrategias en que la población debe resolver por sus propios medios las necesidades de educación, salud y protección social; la asistencia social es residual y modeladora y a su gestión contribuyen activamente las entidades sociales regidas por orientaciones filantrópicas en los términos antes señalados (Rodríguez Cabrero, 2002).

El orden discursivo en voluntariado, describiría coordenadas dominantes enmarcadas en lógicas más individuales y privadas. Desde una suerte de inquietud y/o malestar social, y en actitud crítica ante dichos discursos, se demanda la necesidad de salir de dicha perspectiva dominante, pues se estima que ha conducido a clausurar los derechos ciudadanos de los pobres y a transformar a éstos en objetos de compasión, donde las miradas de pobreza han dejado de ser un asunto de ejercicio de derechos y han pasado a transformarse en un asunto de ética privada (Bengoa, 2005).

Los hallazgos del presente estudio permiten reflexionar acerca de las prácticas concretas que se realizan en ámbitos específicos de intervención social. Reflexionar desde las implicancias discursivas de una práctica en crecimiento, implica no sólo mirar las herramientas concretas con que se promueve una determinada intervención, sino, sus impactos a nivel del proceso de ordenamiento estructural en materia de desigualdades. Promover una práctica desde uno u otro discurso tendrá efectos diferentes en su accionar, y de allí, la necesidad de no sólo reducir el debate disciplinar a las tecnologías de intervención, sino a los componentes éticos y políticos que están detrás de determinadas formas de accionar en temas sociales. Más relevante aún, cuando se trata de prácticas sociales que movilizan recursos humanos y técnicos orientados a modelar la estructura de las desigualdades socia- 
les, promoviendo la formación de determinadas relaciones y actores sociales en un ámbito tan complejo, importante y exigente como el tema de la pobreza.

Esta investigación, limitada en sus alcances, ha pretendido ser un aporte concreto al debate sobre política social en temas de pobreza y desigualdades sociales. Analizar desde un enfoque crítico del discurso permite cuestionar el lugar desde donde se realizan las prácticas sociales, en este caso, el voluntariado. Ninguna intervención es inocente, ni situada en el vacío, sino se implementa desde una lugar concreto, donde los interventores actúan con miradas, perspectivas, en un escenario social que les impone limitaciones, pero también posibilidades.

TEMUCO (CHILE), MARZO 2007

RECIBIDO: ABRIL 2007

ACEPTADO: JUNIO 2007

\section{REFERENCIAS BIBLIOGRÁFICAS}

Adelantado, J.; J. Noguera y X. RAmbla (2000): «El marco de análisis: las relaciones complejas entre estructura social y políticas sociales». En J. Adelantado (coordinador): Cambios en el Estado de Bienestar. Barcelona: Icaria.

ARANGuren, L. (2002): «Modelos de voluntariado». En Ciudadanía, voluntariado y participación. Madrid: Dykinson.

BAÑo, R. (1998): «Participación ciudadana: elementos conceptuales». En E. CORREA y M. NOÉ (editores): Nociones de una ciudadanía que crece. Santiago: FLACSO.

BengoA, J. (2005): «De la libertad». Proposiciones N³4. Santiago: Ediciones SUR. En: www.sitiosur.cl/colecciones.

BetToni, A. y A. CRUZ (2002): «Voluntariado en América del Sur: perfiles, impacto y desafíos». Ponencia presentada en la V Conferencia Internacional de la Sociedad Internacional de Investigación del Tercer Sector. Ciudad del Cabo, Sudáfrica.

Bourdieu, P. (1988): La distinción. Criterios y bases sociales del gusto. Madrid: Taurus.

(1985). ¿Qué significa hablar? Madrid: Akal.

Busso, G. (2001): «Vulnerabilidad social: nociones e implicaciones de políticas para Latinoamérica a inicios del siglo XX». Ponencia presentada en el Seminario internacional de las diferentes expresiones de la vulnerabi- 
lidad social en América Latina y el Caribe.

CARDARELli G. y M. ROSENFELD (1998): Las participaciones de la pobreza. Programas y proyectos sociales. Buenos Aires: Paidós.

CASTEL, R. (1997): La metamorfosis de la cuestión social. Una crónica del salariado. Barcelona: Paidós.

CEPAL (2000): «Equidad, desarrollo y ciudadanía: I. visión global; II. agenda social. En CEPAL: Agenda económica. Economía de América Latina. Bogotá: Alfaomega.

COHEN, I. (1997): «Teoría de la estructuración y praxis social». En A. GIDDENS y J. TURNER (editores): La teoría social hoy. Madrid: Alianza.

CuMSILle, G. y M. GARRETÓN (2005): «Las percepciones de la desigualdad en Chile». Proposiciones No34. Santiago: Ediciones SUR. En: www.sitiosur.cl/colecciones.

De LAIRE, F. (2004): «Pobreza y políticas públicas, tres décadas de evolución: el caso de Chile. Del neoliberalismo ortodoxo al liberalismo social». Ponencia presentada en Encuentro internacional en pobreza un problema de todos, Ciudad de Guatemala. En: www.flacso.edu.gt.

DE LOS Ríos, D. (1999): «Exclusión social y políticas sociales». En OIT: Exclusión social en el mercado de trabajo. El caso de Chile. En: www.ilo.org/public/spanish/index.htm.

DíEZ, A. (2002): «Las ONG como campo de relaciones sociales». En M. REVILLA (coordinadora): Las ONG y la política. Madrid: Istmo.

Doyal, L. e I. Gough (1994): Teoría de las necesidades humanas. Barcelona: Icaria.

Durston, J. (2001): «Capital social. Parte del problema, parte de la solución». Documento presentado en el seminario «En busca de un nuevo paradigma: capital social y reducción de la pobreza en América Latina y el Caribe», Santiago.

DuRston, J. (2000): «¿Qué es el capital social comunitario?». Serie Políticas Sociales $\mathrm{N}^{\circ} 38$. Santiago: CEPAL.

ESPING-ANDERSEN, G. (2000): Fundamentos sociales de las economías postindustriales. Barcelona: Ariel.

FAIRCLOUGH, N. (2003): «El análisis crítico del discurso como método para la investigación en ciencias sociales». En R. WODAK y M. MEYER (compiladores): Métodos de análisis crítico del discurso. Barcelona: Gedisa.

FLACSO (2002): Investigación sobre la conversación social y opinión pública acerca del voluntariado en Chile. Santiago: FLACSO.

FukuYama, F. (2001): Social capital, civil society and development. London: Third World Quarterly.

FUNDACIÓN HOGAR DE CRISTO (2005): www.hogardecristo.com.

FNSP (2005): www.fundacionpobreza.cl.

_ (2002): Juventud universitaria y responsabilidad social. Experiencia y proyecciones del Programa Adopta un Herman@. Santiago: FNSP. 
GARCÍA RocA, J. (2001): En tránsito hacia los últimos: crítica política del voluntariado. Bilbao: Sal Terrae.

_ (1994): Solidaridad y voluntariado. Bilbao: Sal Terrae.

García SELGAS, F. (1994): Teoría social y metateoría hoy. El caso de Anthony Giddens. Madrid: Siglo XXI.

GERGEN, K. (1996): Realidades y relaciones: aproximaciones a la construcción social. Barcelona: Paidós.

Giacoman, C. y M. OPAZO (2002): Responsabilidad social y sistema universitario chileno: visión y expectativas de los jóvenes estudiantes. Santiago: PUC, Instituto de Sociología y Fundación Participa.

GIDDENS, A. (1999): «El futuro del Estado benefactor». Revista Estudios Públicos $\mathrm{N}^{\circ} 74$. Santiago: CEP. En: www.cepchile.cl.

— (1995): La constitución de la sociedad. Bases para la teoría de la estructuración. Buenos Aires: Amorrortu.

_ (1993): Las consecuencias de la modernidad. Madrid: Alianza.

- y J. TURNER (1997): La teoría social hoy. Madrid: Alianza.

Heller, A. (1977): Sociología de la vida cotidiana. Barcelona: Península.

HOLZMANN, R. y S. JORGENSEN (1999): Social protection as social risk management: conceptual underpinnings for the social protection sector strategy paper. Washington: Banco Mundial.

IBÁÑEZ, T. (1994): Psicología social construccionista. Guadalajara: Universidad de Guadalajara.

INSTITUTO NACIONAL DE LA JUVENTUD (2005): www.injuv.gob.cl.

IÑIGUEZ, L. (2003): Análisis del discurso. Manual para las ciencias sociales. Barcelona: UOC.

(1996): Psicología, discursos y poder. Madrid: Visor.

— y C. ANTAKI (1994): «El análisis del discurso en psicología social». Boletín de Psicología No44.

JELIN, E. (1996): «La construcción de la ciudadanía: entre la solidaridad y la responsabilidad». En E. JELIN y E. HERSHBERG (compiladores): Construir la democracia: derechos humanos, ciudadanía y sociedad en América Latina. Caracas: Nueva Sociedad.

JIMÉNEZ DE LA JARA, M. (2003): «Tercer sector y voluntariado en Chile. Recapitulación». Documento de trabajo preparado para el Seminario ONG y voluntariado como agentes de desarrollo social. Antigua.

LiPOVETSKY, G. (1994): El crepúsculo del deber. Barcelona: Anagrama.

MÁrqueZ, F. (2005): «Cultura y movilidad social en los noventa: Santiago, Buenos Aires y Montevideo». Proposiciones No34. Santiago: Ediciones SUR. En: www.sitiosur.cl/colecciones.

— (2002a): «Estigma y apariencias en un Chile desigual». En: Chile el país que viene: ¿de qué país estamos hablando? $\mathrm{N}^{\circ} 7$.

En: www.expansiva.cl/debates/. 
- (2002b): «Los patios traseros de un Chile desigual». En E. CORREA (coordinador): Gobernar los cambios: Chile, más allá de la crisis. Santiago: LOM.

MARTín, L. (2003): «El análisis crítico del discurso. Fronteras y exclusión social en los discursos racistas». En L. IÑIGUEZ (editor): Análisis del discurso. Manual para ciencias sociales. Barcelona: UOC.

— y R. Whittaker (1998): Poder-decir o el poder de los discursos. Madrid: Arrecife/UAM.

MARTíNEZ, M. (1997): «Género, pobreza y exclusión social». En J. F. TEZANOS (editor): Tendencias en desigualdad y exclusión. Madrid: Sistema.

MidePLAN (2002): «Síntesis de los principales enfoques, métodos y estrategias para la superación de la pobreza». En: www.mideplan.cl.

NOÉ, M. (1998): «Ciudadanía y políticas públicas». En E. CORREA y M. NOÉ (editores): Nociones de una ciudadanía que crece. Santiago: FLACSO.

Olavarría, M. (2001): «Pobreza, conceptos y medidas». Documento de Trabajo $\mathrm{N}^{\mathrm{0}} 76 .$. Santiago: Universidad de Chile, Instituto de Asuntos Públicos.

ONETO, L. (2005): «Los discursos sobre la pobreza en Chile. Análisis de sus paradigmas». Proposiciones $\mathrm{N}^{\circ} 34$. Santiago: Ediciones SUR. En: www.sitiosur.cl/colecciones.

PNUD (1995): Informe sobre desarrollo humano. En: www.pnud.cl.

PujAL, M. y J. PUjOL (1995): «Discurso, orden social y relaciones de poder. Una propuesta de ejemplificación en el discurso sobre la maternidad». Revista de Psicología Social Aplicada №5.

PUTNAM, R. (2000): Bowling alone: the collapse and revival of Americam community. New York: Simon and Schuster.

— (1994): Making democracy work. Civic traditions in modern Italy. Princeton: Princeton University Press.

RACZYNSKI, D. (2002): «Equidad, inversión social y pobreza. Innovar en cómo se concibe, diseña y gestiona las políticas y programas sociales». Santiago: Asesorías para el Desarrollo.

En: www.asesoriasparaeldesarrollo.cl.

RodríGUEZ CABRERO, G. (2002): «Los retos de la política social en la era de la globalización». En AA.VV.: La sociedad: teorías e investigación empírica (libro homenaje a José Jiménez Blanco) (507-536). Madrid: CIS.

RoDRíGUEz, D. y R. Ríos (2002): «Las organizaciones sociales en una sociedad compleja». En E. CORREA (coordinador): Gobernar los cambios: Chile, más allá de la crisis. Santiago: LOM.

SANAhUJA, J. (2001): Altruismo, mercado y poder: el Banco Mundial y la lucha contra la pobreza. Barcelona: Intermon Oxfam.

SANDOVAL, J. (2002): «Ciudadanía, gobierno de la subjetividad y políticas sociales». Última Década $\mathrm{N}^{\circ} 17$. Viña del Mar: Ediciones CIDPA. 
Sen, A. (1993): Commodities and Capabilities. New Dheli: Oxford University Press.

SePÚlVEDA, L. (2002): «Sociedad civil: usos y abusos en el tiempo presente». En E. CORREA (coordinador): Gobernar los cambios: Chile, más allá de la crisis. Santiago: LOM.

SCOLLON, R. (2003): «Acción y texto: para una comprensión conjunta del lugar del texto en la (inter)acción social, el análisis mediato del discurso y el problema de la acción social». En R. WODAK y M. MEYER (compiladores): Métodos de análisis crítico del discurso. Barcelona: Gedisa.

Serrano, C. (2005): «Pobreza, capital social y ciudadanía». Proposiciones No34. Santiago: Ediciones SUR. En: www.sitiosur.cl/colecciones.

— y D. RACZYNSKI (2003): «Derechos sociales básicos, superación de la pobreza y protección social ante la vulnerabilidad». Santiago: Asesorías para el Desarrollo. En: www.asesoriasparaeldesarrollo.cl.

TEZANOS, J. (1997): «Tendencias de dualización y exclusión en las sociedades tecnológicas avanzadas. Un marco para el análisis». En J. F. TEZANOS (editor): Tendencias en desigualdad y exclusión. Madrid: Sistema.

WODAK, R. (2003): «El enfoque histórico del discurso». En R. WODAK y M. MEYER (compiladores): Métodos de análisis crítico del discurso. Barcelona: Gedisa.

ZULUETA, S. (2003): «La evolución del voluntariado en Chile entre los años 1990 y 2002». Tesis para optar al grado de Magíster en Sociología, Pontificia Universidad Católica de Chile, Santiago. 